\title{
Efektifitas Edukasi Basic Life Support dengan Media Audiovisual dan Praktik Terhadap Tingkat Pengetahuan dan Keterampilan Mahasiswa Program Studi Ilmu Keperawatan Jenjang D.III Stikes Yarsi Mataram Tahun 2018
}

\author{
Baiq Ruli Fatmawati ${ }^{1)}$, Marthilda Suprayitna ${ }^{1)^{*}}$, Kurniati Prihatin ${ }^{1)}$ \\ Email: marthildasuprayitna@gmail.com \\ 1) Dosen STIKES YARSI Mataram PRODI Keperawatan Jenjang D.III
}

\begin{abstract}
ABSTRAK
Pertolongan pertama pada kejadian henti jantung sangat perlu dilakukan dan harus cepat dilakukan karena kelangsungan hidup lebih tinggi bila korban mendapatkan resusitasi jantung paru atau Basic Life Support. Kejadian kegawatdaruratan henti jantung banyak terjadi diluar rumah sakit atau dekat dengan masyarakat awam. Masyarakat khususnya mahasiswa adalah orang yang harus mengetahui cara bantuan hidup dasar/Basic Life Support. Pelatihan dan pembelajaran sangatlah dibutuhkan untuk meningkatakan kemampuan, pengetahuan dan keterampilan dalam menolong korban. Penelitian bertujuan untuk mengetahui efektifitas edukasi Basic Life Support Dengan Media Audiovisual dan Praktik Terhadap peningkatan Pengetahuan dan Keterampilan Mahasiswa Program Studi Ilmu Keperawatan Jenjang D.III Stikes Yarsi Mataram Tahun 2018. Penelitian ini adalah penelitian kuantitatif, dengan pendekatan pre experimental (one group pre-post test design), dengan sampel sebanyak 30 responden. Hasil dari penelitian ini menunjukkan bahwa terdapat pengaruh edukasi Basic Life Support Dengan Media Audiovisual dan Praktik Terhadap peningkatan Pengetahuan dan Keterampilan Mahasiswa dengan nilai yang signifikan yaitu $\mathrm{p}=0,000(\mathrm{p}<0,05) .:$ Ada pengaruh efektifitas edukasi Basic Life Support Dengan Media Audiovisual dan Praktik Terhadap Tingkat Pengetahuan dan Keterampilan Mahasiswa Program Studi Ilmu Keperawatan Jenjang D.III Stikes Yarsi Mataram Tahun 2018.
\end{abstract}

Kata kunci: $B H D$, edukasi ketrampilan, edukasi pengetahuan.

\begin{abstract}
First aid in the event of cardiac arrest is very necessary and should be done quickly because life sustainability is higher if the victim gets heart resuscitation or Basic Life Support. The events of emergency cardiac arrest often occur outside the hospital or close to the common people. The community, especially student is the one who must know about Basic Life Support. Training and learning is needed to improve skills especially in knowledge and skill in helping the victims. To determine the effect of Basic Life Support with educational Audiovisual and practice on the level of knowledge and skill of college students Student Diploma of Nursing STIKES YARSI of Mataram at 2018. This study used quantitative pre experimental method with one group pre-post test design. This research used a design quantitative pre experimental method with one group pre-post test design, with a number of samples of 30 respondents. The results of the knowledge variable obtained a value of $Z$ of $-3,326$ with $p$ value $=0,0001$ and in the skill variable obtained an $Z$ value of $-4,684$ with $p$ value 0,0001. There is the influence of Basic Life Support training on the knowledge and skills of of college students There is an effect of Basic Life Support education on the level of knowledge and skills students after getting Audiovisual and practice education.
\end{abstract}

Keywords: Basic Life Support, skills education, knowledge education. 


\section{A. LATAR BELAKANG}

Kegawatadaruratan dapat terjadi kapan saja, dimana saja dan umumnya mendadak serta tidak terencana, gawat adalah kondisi yang mengancam nyawa dan darurat adalah perlunya tindakan segera untuk menangani ancama nyawa korban [1]. Henti jantung maupun henti napas adalah salah satu permasalahan yang mengancam jiwa dan bisa berakibat kematian bila terlalu lama dalam pertolongannya. Angka kejadian henti jantung atau cardiac arrest berkisar 10 dari 100.000 orang normal yang berusia dibawah 35 tahun dan per tahunnya mencapai sekitar 300.000-350.000 kejadian [2].

Henti jantung dalam kurun waktu 10 tahun terakhir ini bagian dari 10 penyebab kematian dengan 253 kasus dan menempati urutan ke empat. Kasus kejadian henti jantung kebanyakan terjadi di luar rumah sakit. Hal ini seperti disampaikan American Heart Association [3] bahwa kasus Out-of- Hospital Cardiac Arrest (OHCA) terdapat sekitar 359,400 dan kasus InHospital Cardiac Arrest (IHCA) terdapat sekitar 209,000 dari data tahun 2013. Tingkat pertolongan pada kasus tersebut tercatat, hanya 40,1\% dari kasus OHCA yang memperoleh bantuan hidup dasar dan pertolongan tepat [3].

Kasus henti jantung dapat terjadi dimanapun, di masyarakat, di luar rumah sakit maupun di dalam rumah sakit. Kemungkinan bertahan hidup pada penderita henti jantung di luar rumah sakit atau pre-hospital menurun 7-10\% tiap menit sejak dimulainya henti jantung [4]. Di Amerika dan Kanada dari jumlah henti jantung yang terjadi di luar rumah sakit hanya setengahnya dilakukan tindakan resusitasi atau bisa dikatakan 50-55\% yang dilakukan [5]. Pertolongan pertama pada kejadian henti jantung sangat perlu dilakukan dan harus cepat dilakukan karena kelangsungan hidup lebih tinggi bila korban mendapatkan Cardiopulmonary Resusciation (CPR). Menghubungi Emergency Call dan CPR yang diberikan segera dapat meningkatkan jumlah orang yang mendapatkan kesempatan hidup [6].

Pada sebagian besar kasus, dari awal kejadian pasien terkena henti jantung dan henti napas sampai tiba di layanan kegawatdaruratan membutuhkan waktu yang cukup lama. Selain jarak tempuh, prognosis pasien juga dipengaruhi oleh tatalaksana awal resusitasi jantung paru. Hingga saat ini, hanya sebagian kecil dari pasien henti jantung yang menerima resustasi jantung paru (RJP) dari masyarakat yang menyaksikan di tempat kejadian, hal ini disinyalir akibat kurangnya pengetahuan masyarakat terkait tindakan RJP yang harusnya dilakukan kepada pasien di tempat kejadian [7].

Keterampilan melakukan resusitasi jantung paru (RJP) harus dimiliki setiap orang untuk mengurangi dampak buruk atau keparahan gejala sisa pasien henti jantung. Keterampilan dalam tindakan pertolongan awal ini bertujuan untuk oksigenasi darurat mempertahankan fungsi jantung paru melalui ventilasi dan sirkulasi buatan. Dengan demikian nantinya diharapkan ventilasi dan sirkulasi dapat pulih spontan sehingga mampu melakukan oksigenasi secara mandiri. Hal ini akan memberikan prognosis yang lebih baik pada pasien, menurunkan angka morbiditas dan mortalitas pasien. Kemampuan untuk melakukan CPR lebih didasarkan pada kekuatan tubuh daripada usia.

Aspek dasar pertolongan pada henti jantung mendadak adalah bantuan hidup dasar (BHD), aktivasi sistem tanggap darurat, RJP sedini mungkin [8]. Pada korban henti jantung penting halnya untuk melakukan BHD di menit-menit awal hal ini tentunya dapat meningkatkan angka pasien bertahan hidup sebanyak $4 \%$ dan pada pasien napas spontan 40\% [9]. Pelayanan kesehatan kegawatdaruratan sehari-hari merupakan kewajiban yang harus dimiliki oleh semua orang. Pengetahuan dan sikap dari manusianya sendiri yang akan mempengaruhi kecepatan dan ketepatan dalam melakukan pertolongan.

Pengetahuan bantuan hidup dasar (BHD) merupakan sebuah pengetahuan dan keterampilan karena jika hanya mengetahui teorinya saja tanpa melakukan latihan atau praktek, maka mental tidak terlatih ketika benar- 
benar menghadapi kejadian sebenarnya. Pertolongan dengan teknik BHD yang benar adalah sebuah kegiatan yang harus dilakukan demi terciptanya penyelematan korban dengan tepat dan cepat. Penolong dalam memberikan BHD minimal harus memiliki pengetahuan dalam pertolongan dan pernah berlatih serta memiliki penanganan medis dasar. Pengetahuan masyarakat mengenai BHD masih rendah. Sebagaimana dalam penelitian Hutapea [10], pada masyarakat bahwa 50\% masyarakat masih tergolong berpengetahuan kurang, 30,4\% tergolong cukup dan 19,6\% baik. Hal ini juga sejalan dengan penelitian Rahmawaty [11], mengenai pengetahuan Basic Life Support pada mahasiswa keperawatan di Gorontalo hasilnya juga masih kurang. Hasil penelitian gambaran pengetahuan bantuan hidup dasar didapatkan $48,8 \%$ responden memiliki pengetahuan kurang, dan $40,2 \%$ responden memiliki pengetahuan cukup, sedangkan $11,0 \%$ responden memiliki pengetahuan baik.

Kurangnya pengetahuan masyarakat khususnya pada mahasiswa harus ditingkatkan agar tercapainya hasil yang baik. Peningkatan jumlah penolong atau relawan khususnya untuk BHD harus ditingkatkan dengan peningkatan pengetahuan dan ketrampilannya. Mahasiswa merupakan agent of change untuk menjadi perubah dan siap tanggap dalam keadaan kegawatdaruratan khususnya kegawatan henti jantung dan henti napas. Menolong kegawatan henti jantung dan henti napas dibutuhkan mental dan kesiapan dalam materi. Pelatihan dalam mendapatkan ilmu BHD bisa didapatkan dari berbagai macam metode dan menggunakan kemajuan teknologi media Audiovisual untuk berlatih.

Media Audiovisual adalah bagian yang tidak terpisahkan untuk tercapainya tujuan pendidikan yang berasal dari proses belajar mengajar [12]. Media pembelajaran yang tepat dapat mempengaruhi dalam penyajian pesan dan informasi sehingga dapat meningkatkan dan memperlancar proses belajar serta hasil belajar [13].

\section{B. METODE PENELITIAN}

Penelitian ini adalah penelitian kuantitatif, penelitian yang bertujuan untuk menilai efektifitas edukasi Basic Life Support dengan media Audiovisual dan Praktik Pengetahuan dan Keterampilan Mahasiswa Program Studi Ilmu Keperawatan Jenjang D.III Stikes Yarsi Mataram Tahun 2018. Jenis penelitian yang akan digunakan dalam penelitian ini adalah dengan menggunakan metode pre experimental dengan design rancangan penelitian ini menggunakan one group pre-post test design. Sampel dalam penelitian ini sebanyak 30 responden.

Analisis data yang digunakan dalam penelitian ini adalah uji Wilcoxon. Instrument yang digunakan dalam penelitian ini adalah kuesioner untuk mengetahui sejauh mana tingkat pengetahuan, dimana kuesioner ini telah dilakukan uji validitas dan realibilitas. Untuk instrument keterampilan menggunakan lembar observasi bantuan hidup dasar dari Yayasan Ambulans Gawar Darurat 118 Jakarta.

Kriteria Inklusi: a) Mahasiswa Program Studi Ilmu Keperawatan Jenjang D.III Stikes Yarsi Mataram, b) Mahasiswa yang belum pernah mengikuti pelatihan, c) Mahasiswa yang bersedia mengisi informed consent.

Penelitian dilakukan di STIKES Yarsi Mataram pada bulan Desember 2018.

\section{HASIL DAN PEMBAHASAN}

\section{Hasil Univariat}

Tabel 1. Data Demografi

\begin{tabular}{|c|c|c|}
\hline $\begin{array}{c}\text { Karakteristik } \\
\text { responden }\end{array}$ & Frekuensi & $\%$ \\
\hline Jenis kelamin & & \\
\hline Laki-laki & 11 & 37.7 \\
\hline Perempuan & 19 & 63.3 \\
\hline Usia (tahun) & 18 & 60.0 \\
\hline $20-25$ & 12 & 40.0 \\
\hline $25-30$ &
\end{tabular}

Berdasarkan tabel diatas sebagian besar responden dalam penelitian ini adalah perempuan sebanyak 19 orang $(63.3 \%)$, dengan usia rata-rata 20-25 tahun sebanyak 18 orang $(60 \%)$. 


\section{Hasil Bivariat}

Tabel 2. Efektifitas Edukasi Basic Life Support Dengan Media Audiovisual dan Praktik terhadap Tingkat Pengetahuan Mahasiswa Program Studi Ilmu Keperawatan Jenjang D.III Stikes Yarsi Mataram Tahun 2018

\begin{tabular}{|c|c|c|c|c|}
\hline & $\mathrm{N}$ & Mean & Nilai Z & $\mathrm{p}$ \\
\hline Pengetahuan & 30 & $4,87 \pm$ & $-3,32$ & 0,0001 \\
sebelum & & 2,129 & & \\
\cline { 1 - 3 } $\begin{array}{c}\text { Pengetahuan } \\
\text { sesudah }\end{array}$ & 30 & $\begin{array}{c}7,33 \pm \\
2,090\end{array}$ & & \\
\hline
\end{tabular}

Berdasarkan hasil penelitian diatas, bahwa nilai rata-rata pengetahuan responden sebelum

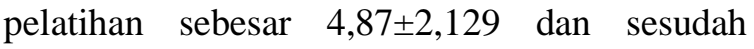
pelatihan nilai rata-rata meningkat menjadi $7,33 \pm 2,090$.

Hasil analisis bivariat dengan menggunakan uji Wilcoxon, diperoleh nilai Z sebesar $-3,326$ dan nilai significancy sebesar $0,0001(\mathrm{p}<0,05)$. Hasil uji statistik ini dapat disimpulkan bahwa ada pengaruh edukasi Basic Life Support terhadap tingkat pengetahuan mahasiswa Program Studi Ilmu Keperawatan Jenjang D.III Stikes Yarsi Mataram.

Tabel 3. Efektifitas Edukasi Basic Life Support Dengan Media Audiovisual dan Praktik terhadap Tingkat Keterampilan Mahasiswa Program Studi Ilmu Keperawatan Jenjang D.III Stikes Yarsi Mataram Tahun 2018

\begin{tabular}{|c|c|c|c|c|}
\hline & $\mathrm{N}$ & Mean & Nilai Z & $\mathrm{p}$ \\
\hline $\begin{array}{c}\text { Keterampilan } \\
\text { sebelum }\end{array}$ & 30 & $\begin{array}{c}2,83 \\
\pm 0,950\end{array}$ & & \\
& & \multirow{2}{*}{$-4,684$} & 0,0001 \\
$\begin{array}{c}\text { Keterampilan } \\
\text { sesudah }\end{array}$ & 30 & $\begin{array}{c}4,70 \\
\pm 0,466\end{array}$ & & \\
\hline
\end{tabular}

Berdasarkan hasil penelitian diatas, bahwa nilai rata-rata keterampilan responden sebelum pelatihan sebesar $2,83 \pm 0,950$ dan sesudah pelatihan nilai rata-rata meningkat menjadi $4,70 \pm 0,466$.

Hasil analisis bivariat dengan menggunakan uji Wilcoxon, diperoleh nilai $\mathrm{Z}$ sebesar $-4,684$ dan nilai significancy sebesar $0,0001(\mathrm{p}<0,05)$. Hasil uji statistik ini dapat disimpulkan bahwa ada pengaruh Edukasi Basic Life Support Dengan Media Audiovisual dan Praktik terhadap Keterampilan Mahasiswa Program Studi Ilmu Keperawatan Jenjang D.III Stikes Yarsi
Mataram.

\section{Pembahasan}

Hasil penelitian menunjukan bahwa nilai rata-rata pengetahuan responden sebelum pelatihan sebesar 4,87 $\pm 2,129$ dan sesudah pelatihan nilai rata-rata meningkat menjadi $7,33 \pm 2,090$. Hasil analisis bivariat dengan menggunakan uji Wilcoxon, diperoleh nilai $\mathrm{Z}$ sebesar $-3,326$ dan nilai significancy sebesar $0,0001$ ( $\mathrm{p}<0,05)$. Hasil uji statistik ini dapat disimpulkan bahwa ada Efektifitas Edukasi Basic Life Support Dengan Media Audiovisual dan Praktik terhadap Tingkat Pengetahuan Mahasiswa Program Studi Ilmu Keperawatan Jenjang D.III Stikes Yarsi Mataram Tahun 2018. Karena telah terjadi peningkatan dari 4,87 menjadi 7,33 point (peningkatan sebesar 2,46 point).

Setiap media yang digunakan dalam menyampaikan informasi memiliki pengaruh tersendiri terhadap kemampuan seseorang dalam menyerap informasi. Menurut Young dalam Ningsih [14] menjelaskan bahwa presentase peningkatan kemampuan seseorang 90\% didapatkan dari melihat langsung, mempraktikan serta memperagakan pengetahuan dan keterampilan yang diajarkan.

Pembelajaran dengan metode melihat Audiovisual dan praktik memiliki waktu pembelajaran yang lebih lama. Adanya arahan, instruksi dan perhatian langsung dari fasilitator/ instruktur adalah faktor-faktor yang mempengaruhi kemampuan dalam menangkap suatu pengetahuan maupun keterampilan.

Notoadmodjo [15] mengatakan pengetahuan adalah hasil tahu dari manusia dan ini terjadi setelah orang mengadakan penginderaan terhadap suatu objek tertentu. Dan beliau juga menjelaskan bahwa semakin tinggi tingkat pengetahuan seseorang, maka semakin tinggi pula seseorang memahami pentingnya melakukan kegiatan untuk mencapai tujuan.

Pengembangan suatu pengetahuan terlihat dari kemampuan seseorang mampu mengaplikasikannya salah satunya dalam bentuk 
keterampilan. Menurut Ningrum [16] proses pengembangan keterampilan dapat dilakukan setelah kegiatan pembelajaran tindak lanjut dari kegiatan pembelajaran. Pengembangan keterampilan harus dimulai dari apa yang dikuasai mahasiswa ke keterampilan yang belum dikuasainya.

Hal ini sesuai dengan teori yang dikemukakan oleh Cristian [17] bahwa pengetahuan yang baik sangat berpengaruh pada kemampuan yang baik pula, kemampuan seseorang menerapkan pengetahuan yang dimiliki kedalam bentuk tindakan, dimana harus memiliki keterampilan baik dalam komunikasi efektif, objektifitas dan kemampuan dalam membuat keputusan klinis secara tepat dan tepat agar perawatan setiap pasien menjadi maksimal.

Hasil penelitian menunjukan bahwa nilai rata-rata keterampilan responden sebelum pelatihan sebesar 2,83 $\pm 0,950$ dan sesudah pelatihan nilai rata-rata meningkat menjadi 4,70 $\pm 0,466$ Hasil analisis bivariat dengan menggunakan uji Wilcoxon, diperoleh nilai $\mathrm{Z}$ sebesar $-4,684$ dan nilai significancy sebesar 0,0001 ( $\mathrm{p}<0,05)$. Hasil uji statistik ini dapat disimpulkan bahwa ada peningkatan keterampilan Mahasiswa Program Studi Ilmu Keperawatan Jenjang D.III Stikes Yarsi Mataram Tahun 2018 dari 2,83 menjadi 4,70 point (peningkatan sebesar 1,47 point).

Hasil penelitian ini sejalan dengan Turambi [18] yang menyatakan ada pengaruh pelatihan bantuan hidup dasar terhadap peningkatan keterampilan siswa dengan nilai $\mathrm{p}=0,000<0.05$. Hal ini menunjukkan bahwa pelatihan bantuan hidup dasar memberi hasil yang bermakna.

Menurut Pirton \& Nazmudin [19] Bantuan Hidup Dasar (BHD) merupakan usaha sederhana yang dilakukan untuk mengatasi keadaan yang mengancam nyawa seseorang sehingga dapat mempertahankan hidupnya untuk sementara. Bantuan Hidup Dasar dilakukan sampai bantuan atau pertolongan lanjutan datang. Bantuan hidup dasar merupakan bagian dari pengelolaan gawat darurat medik yang bertujuan untuk mencegah berhentinya sirkulasi atau berhentinya respirasi
[20]. Keadaan para korban kecelakaan dapat semakin buruk. atau berujung pada kematian jika tidak ditangani dengan cepat [21].

Bantuan Hidup Dasar dapat diartikan sebagai usaha yang dilakukan untuk mempertahankan kehidupan seseorang yang sedang terancam jiwanya [20]. Frame juga menyatakan bahwa Bantuan Hidup Dasar harus diberikan pada korban yang mengalami henti nafas, henti jantung, dan perdarahan. Keterampilan seseorang agar dapat memberikan BHD dengan baik harus melalui pelatihan.

Pelaksanaan keterampilan seseorang harus mempunyai dasar yang telah didapat baik berupa informasi ataupun berupa pelatihan. Pengembangan keterampilan harus dimulai dari apa yang dikuasai seseorang, keterampilan yang belum dikuasainya. Hal ini menyatakan bahwa pelatihan menjadi lebih efektif untuk meningkatkan keterampilan yang sesungguhnya, hal ini tidak lepas dari pemberian pelatihan.

Proses pengembangan keterampilan dapat dilakukan setelah kegiatan pembelajaran, tindaklanjut dan pengembangan suatu pengetahuan yang terlihat dari kemampuan seseorang mampu mengaplikasikannya, salah satunya dalam bentuk keterampilan [16].

Faktor-faktor yang dapat mempengaruhi keterampilan menurut Bertnus [22] yaitu pengetahuan, pengalaman, keinginan/motivasi. Seorang harus memiliki faktor-faktor tertentu yang dapat mempengaruhi keterampilan, hal ini berkaitan dengan tindakan-tindakan yang harus dilakukan untuk membangun suatu keterampilan yang baik. Mahasiswa harus memiliki keterampilan yang profesional, keterampilan (kompetensi) khusus tersebut bisa didapatkan melalui pendidikan dan pelatihan tentang kegawatdaruratan. Keterampilan tersebut harus selalu ditingkatkan atau dikembangkan dan dipelihara sehingga menjamin perawat dapat melaksanakan peran dan fungsinya secara professional [23].

Hasil penelitian yang dilakukan oleh Chaundary, Parikh, dan Dave [24] yang menjelaskan bahwa terjadi peningkatan 
keterampilan RJP dapat dilakukan dengan cara mengikuti pelatihan BHD. Pelatihan yang berkesinambungan diperlukan untuk menyegarkan kembali pengetahuan dan keterampilan. Keenan, Lamacraft, dan Joubert [25] menjelaskan bahwa penyegaran pelatihan harus dilakukan setiap 6-12 bulan untuk mempertahankan kemampuan skill BHD, hal ini disebabkan karena keterampilan mahasuswa tentang BHD khususnya RJP dapat menurun setelah 2 minggu dilakukan pelatihan. Frame [20] menyatakan bahwa bantuan hidup dasar (BHD) dapat diajarkan kepada siapa saja. Setiap orang dewasa seharusnya memiliki keterampilan BHD, bahkan anak-anak juga dapat diajarkan sesuai dengan kapasitasnya, agar dapat memberikan pertolongan keselamatan dengan segera.

\section{KESIMPULAN}

Berdasarkan hasil penelitian yang telah dilakukan tentang Efektifitas Edukasi Basic Life Support Dengan Media Audiovisual dan Praktik terhadap Tingkat Pengetahuan dan Keterampilan Mahasiswa Program Studi Ilmu Keperawatan Jenjang D.III Stikes Yarsi Mataram Tahun 2018, dapat disimpulkan sebagai berikut :

1. Mayoritas responden dalam penelitian ini adalah perempuan dan sebagian besar berusia dewasa muda .

2. Terdapat perbedaan yang signifikan pada tingkat pengetahuan sebelum dan sesudah edukasi Basic Life Support Dengan Media Audiovisual dan Praktik pada mahasiswa.

3. Terdapat perbedaan yang signifikan pada keterampilan sebelum dan sesudah edukasi Basic Life Support Dengan Media Audiovisual dan Praktik pada mahasiswa.

Hasil penelitian ini diharapkan mahasiswa mampu mengetahui, memahami, tentang Basic Life Support (BLS) dan mampu mengaplikasikan hasil pengetahuannya tentang Basic Life Support (BLS) sehingga bila mendapat korban atau pasien dengan kegawatdaruratan dapat segera tertangani.

Bagi peneliti selanjutnya agar menggunakan metode pelatihan lain seperti small group discussion atau peer group serta menggunakan media lain yang lebih menarik, untuk menambah variabel penelitian dalam aspek perilaku atau aspek lain dengan metode pengumpulan data menggunakan instrumen lain seperti teknik wawancara dan lain-lain.

\section{DAFTAR PUSTAKA}

[1] Jakarta Medikal Senter 119. (2013). Jakarta Medical Service 119 Training Division. Jakarta.

[2] American Heart Association. (2015). Part 5: Adult Basic Life Support and Cardiopulmonary Resusitation Quality: 2015 American Heart Association Guidelines Updated for Cardiopulmonary Resusitation and Emergency Cardiovascular Care. AHA Journals, 132 (18) : 415-435

[3] American Heart Association (AHA). (2013). 2013 ACCF/AHA guideline for the management of heart failure: A report of the American College of Cardiology Foundation/American Heart Association task force on practice guidelines. JAm Coll Cardio, 62(16), e240-e327.

[4] American Heart Association (AHA). (2011). Metabolic risk for cardiovascular disease edited by Robert H. Eckel. Wiley Blackwell Publishing.

[5] American Heart Association (AHA). (2010). Highlights of the 2010 American Heart Association guidelines for CPR and ECC. Resuscitation.

[6] Sudden Cardiac Arrest Foundation. (2015). Dikutip dari http://www.scaaware.org/sca-news/aha-releases-2015heart-andstroke-statistics pada tanggal 25 Maret 2019.

[7] Wissenberg, M. et al. (2013). Association of national initiatives to improve cardiac arrest management with rates of bystander intervention and patient survival after outof-hospital cardiac arrest. Jama, 310 (13), pp. 1377-84. Available at: http://www.ncbi.nlm.nih.gov/pubmed/

[8] Kleinman, M.E. et al., (2015). Part 5: Adult Basic Life Support and cardiopulmonary resuscitation quality: 2015 American Heart 
Association guidelines update for cardiopulmonary resuscitation and emergency cardiovascular care. Circulation, 132(18), pp.S414-S435.

[9] Botha, L. et al., (2017). Knowledge of cardiopulmonary resuscitation of clinicians at a South African tertiary hospital Knowledge of cardiopulmonary resuscitation of clinicians at a South African tertiary hospital., 6190.

[10] Hutapea, E. (2012) Gambaran Tingkat Pengetahuan Polisi Lalu Lintas Tentang Bantuan Hidup Dasar di Kota Depok.

[11] Rahmawaty Latif. (2015). Gambaran Pengetahuan Bantuan Hidup Dasar (BHD) Pada Mahasiswa Program Studi Ilmu Keperawatan Universitas Negeri Gorontalo.

[12] Arsyad, Azhar. (2011). Media Pembelajaran. cetakan ke-15. Jakarta: Rajawalli Pers.

[13] Sukiman. (2012). Pengembangan Media Pembelajaran. Yogyakarta: Pustaka Insan Madani.

[14] Ningsih, V. S. (2011). Pengaruh Pendidikan Kesehatan Terhadap Tingkat Pengetahuan Remaja Putri tentang SADARI di SMK Negeri 1 Godean.

[15] Notoatmodjo. S. (2010). Metode Penelitian Kesehatan. Jakarta. Rineka Cipta

[16] Ningrum, Epon. (2007). Penelitian tindakan kelas, panduan praktis dan contoh. Yogyakarta: Ombak.

[17] Cristian L., Suarnianti, Ismail H., (2013). Pengetahuan Perawat tentang Kegawatan Nafas dan Tindakan Resusitasi Jantung Paru pada Pasien yang mengalami Kegawatan Pernafasan di Ruang ICU dan UGD RSUD Kolonodale Propinsi Sulawesi Tengah. Vol. 3. No. 4

[18] Turambi. (2016). Pengaruh Pelatihan Bantuan Hidup Dasar (BHD) Terhadap Peningkatan Pengetahuan dan Keterampilan Siswa kelas XI Dan XII SMA Negeri 2 Langowan.

[19] Pirton, L \& Nazmudin. (2015). BTCLS \& Disaster Management. (Edisi Pertama). Tanggerang Selatan: YPIKI (Yayasan Pelatihan Ilmu Keperawatan Indonesia.

[20] Frame. (2010). PHTLS: basic and advanced prehospital trauma life support. Jakarta: EGC.
[21] Sunyoto. (2010). Presentasi Case Study, simulasi.http://fkm.unsri.ac.id/index.ph

[22] Bertnus. (2009). Faktor yang mempengaruhi keterampilan.http://digilid.unimus.ac.id/fil es/disk1/115/.

[23] Musliha. (2010). Keperawatan Gawat Darurat. Yogyakarta: Nuha Medika

[24] Chaudhary A, Parikh H, \& Dave V. (2011). Current scenario: Knowledge of Basic Life Support in medical college. Nat J Med Res, $1: 80-82$

[25] Keenan, M. Lamacraft, G., \& Joubert, G. (2009). A Survey Of Nurse Basic Life Support knowledge and training at a tertiary hospital. African Journal Of Health proffesions Education, 1(1) 